\title{
Adequation of a Virtual Immersive Environment for a Learning-Teaching Interaction Using the Limem 3d Method
}

\author{
Diego Mauricio Torres Arias ${ }^{1}$ and HelmuthTrefftz ${ }^{2}$ \\ 1. Department of software engineer, Universidad EAFIT \\ 2.Department of Computer and Systems, Laboratory of Virtual Reality, Universidad EAFIT, Medellin, Colombia
}

\begin{abstract}
Over the past thirty years, since the advent of the Web, the potential use of virtual environments for teaching-learning processes has undergone an exponential increase, leading us quickly from the use of web pages to social networks, and from these to virtual immersive environments such as Second Life among others. Those kind of 3D platforms (Immersive Virtual Environments) or metaverses are representations of real or imaginative worlds created on the digital world with the purpose of allowing users to live impossible situations and experiences without the limitations of the real world. Users on these worlds are represented by avatars that interact in representation of users. These virtual worlds are used for business processes, research and education. In relation to the teaching and learning processes, metverses are widely used for research and application of educational processes, especially in the area of languages learning. The purpose of this paper is to describe the process of using the experimental 3D LIMEM method, specifically the learning path branch, for adapting an immersive virtual environment to be used as a virtual teaching-learning tool of English as a second language.
\end{abstract}

Key words: Avatar, metaverse, virtual reality, 3D LIMEM, learning path.

\section{Introduction}

History shows us that technological advances have been vital in the construction of new paradigms of teaching in different educational branches. Approaching the classroom, teacher and knowledge to the student has been the focus of such developments. Currently, teachers need to move from the classroom to the computer through the use of web pages, Web Quest, Wikis, forums, study groups, platforms such as model and blackboard, social networks and knowledge in the cloud and others; these paradigms lead us to manage high levels of complexity, to live in diversity of opinion based on personal knowledge provided from a network as it narrates "the model for learning in the digital age" [1]. The next step in the evolutionary chain of virtual learning environments is

Corresponding author: Diego Mauricio Torres Arias, assistant professor, research fields: education and 3D worlds. E-mail: diegoma363@gmail.com. the emergence of virtual immersive and semi-immersive environments, among them Unity (http://unity3d.com/), (http://www.vastpark.com/), OpenSimm (http://opensimulator.org/wiki/Main_Page), and second life (Linden labs- http://secondlife.com/); being the last one the first in appearing as the sums of technology not only on 3D visualization and immersivity, but also as integrated technology of chat, IP Voice and interaction in real time through customized avatars, with a high quality in the process of immersion to the student and giant possibilities in many fields, and the language study among them.

Created in 2003, Second Life (by Lindenlabs) is the most active and used VIW (virtual immersive world) in higher education, in which universities and other education centers make active presence [2]. An example of this is offered by recent research focused on sociological, psychological and economic aspects that are focused taking advantage of second life as a 
support to people with social challenges such as overcoming social anxieties and fears, or testing the grade of satisfaction of participating on second life according to their gender [3]. In the case that concerns us, languages, there already exist some projects, organizations, and schools on SL (second life) dedicated to the teaching of English applying traditional philosophies such as constructivist and even creating new paradigms as dogma or SLOODLE, among them we find AVALON http://www.avalonlearning.eu - and NIFLAR -http://www.niflar.eu-(experimental worlds for the language teaching of English in 3D), KAMIMO PROJECT (Island on Second Life) ASIMIL8, VIRTLANTIS (island on Second Life to the study of a second language), TEACH YOU TEACH ME (island on buddy network - http://tuwien.esnaustria.org/-) and EDUNATION (island on Second Life to the learning of languages). In the area of educational projects for example, AvatarEnglish.com as school of learning. Edunation II and III, special island where there are located different teaching centers; and educational institutions paths of great global relevance as the InstitutoTecnologico de Las Americas (ITLA), Harvard, Massachusetts Institute of Technology (MIT) and Stanford University, and in the colombian case, Los Andes University. These facts indicate us that the implementation of these new technologies in the field of teaching-learning “isn't a technological problem at all, as a social challenge that require an educational solution” [4].

Thus, some visionaries seek to incorporate the new ICTs and the 3D worlds to generate a new educational paradigm with greater force in the field of the second language teaching, a fact thateach day is taking importance for the future of students and professionals. However, none of the previous efforts, despite of the innovative nature of previous works, have focused on making a method that permits the adequacy of 3D virtual worlds characteristics according to a previous planned situation or strategy, such us the use of learning path, simulation, emulation and role play.

The purpose, then, of this paper, is to perform a study on the adequacy of the environment used to these jobs according to LIMEM 3D Method [5] guidelines in juxtaposition with classical classroom teaching strategies, taking advantage of Second Life complete world, different environments, information extracted from web and the student's taste about electronic media.

Section 2, contains several references about other released works related with the topic of this paper. Section 3, define the object of study, presents and summarizes LIMEM 3D Method Branches. Section 4, shows a direct application of LIMEM 3D Method, specifically learning path branch. Finally, Section 5 presents all conclusions about this topic.

\section{Related Works}

Among the many works related to the use of immersive 3D learning environments, several are highlighted internationally, efforts of different universities and centers of study that explore new technologies for teaching-learning, this is the case of the School of Science at the University of Denver, that has reproduced their campus in Secondlife under the name of "Science School". According to Jeffrey Corbin, the university makes experiments that would be dangerous in real life [6]. The ILR (institute for labor relationships) at Cornell University performed research exercises in second life about unusual themes and used formal numerical methods for the interpretation of the data, a clear example is the experiment called "Living Large: The Powerful overestimate their own height study 3” [7], in which they explored the correlation of the perception of an individual power and her avatar's height in Second Life.

Other important examples are found in Harvard University, New York University or MIT, all of them highly internationally, which offer their students educational interactions on 3D virtual environments. 
Within these institutions, Harvard University stands out with its course on Second life called: "Cyber One: law in the court of public opinion”, which is designed specifically for law school and its Extension School. Other courses are implemented on virtual environments offered as academic experiences such as: HRSA Play2 Train, which simulates a hospital environment in which students must attend different types of emergencies using their avatar. In Colombia, universities such as EAFIT make research works on the SecondLife platform through an island called Telling East (EAFIT Colombia - Land 6144 sq / Corner Ocean Front / Class 5/Mature/Terraform, Tellings Beach East), a place where students have the opportunity to try constructions on $3 \mathrm{D}$ or in the case of SENA whose main island is SENA Colombia 3d (aaSENA 3D virtual SENA), and which has built a great center to show to the world the Colombian coffee, and a virtual hospital and a virtual farm. Minute of God (a Colombian College) has also taken significant research on the subject, highlighting its work: “3D Virtual Environments, pedagogical alternative to the Foster of the Collaborative Learning and Management Knowledge in Uniminuto" investigation conducted by Juan C. FranciQuinche and L. Gonzalez, and which is intended to lay the groundwork for a future virtual Uniminuto using Sloodle experiences [8].

We also find universities like the Carlos III University, Seville University, Rosario University, Aveiro University, Navarra Public University and do Porto University among others.

So far, in the directory of Second Life's owners there are more than 95 educational institutions.

However, all these efforts are aimed at building a site to measure or develop a specific program unlike our research which neither aims to build an educational world through Second Life metaverse, nor create a complete academic program to be followed. Instead, the idea is to get is an adequacy of the 3D immersive virtual world where a teaching-learning interaction for the purpose of learning of a second language takes place, instead of the traditional classroom learning environment.

To achieve the goal we propose to develop and to design of guidelines and implementation of e-activities in 3D virtual worlds [9] outlined by steps raised in learning path branch, based on the experimental method 3D LIMEM.

\section{Context}

\subsection{Definition the Subject of Study}

In order to carry out the development of a teaching-learning interaction in the best way, it is recommended to choose a very specific thematic but also with an intermediate degree of complexity, which can be developed in a reasonable time, which is commensurate with the student level (A2 in the Common European Framework scale) chosen for the process and that is part of the academic program of an institution with a certified program. For the purposes of this experiment, the thematic of present simple was chosen, specifically the use of the third person rules (use of inflection in verb endings and related auxiliaries), through the context of describing the daily routine of a student and building or answering questions about it. Therefore, it was necessary to use a branch of the design method LIMEM 3D (Learning immersive 3D environment Method), build a blog based on the thematic to be taught and to adapt a simple environment of interaction with the student through Second Life, using a portion of the 3D land of the Universidad EAFIT.

\subsection{Experimental 3D LIMEM Method Branches.}

The experimental 3D LIMEM Method [5] has been designed as a useful set of guidelines for teaching-learning interactions through 3D environments. It is actually developing and offers four possibilities in its application, as is showing:

Learning path: This branch of application intends to build a path through which learners understand and 
practice the suggested topic. This method application uses four different windows or walls (into the 3D Virtual World), in order to present the topic to study (with their principal aspects). This branch aims to present the principal aspects of the topic from different perspectives, presents a route with proposed activities to develop during the tour within the 3D world - chosen environments) and presents Links test about thematic chosen.

Simulation: this branch focuses on simulate real or imaginative situations, with complete details, into a controlled environment through avatars (that represent real players of real simulated situation or imaginary personages proposed and developed 3D sceneries (it have to be include very specific artifacts and real simulated environment conditions) in order to analyze situations in a deep way. This branch is focused on reactions, final results or possible states.

Emulation: Through this line, 3D LIMEM Method applies design and function of real machines (Simulate physical machine aspects and emulate functions, shape, states and interactions) as well as Emulation functions of machines that in real world are still under design. It is useful for training in machines uses, usability test or design test.

Role play: it is similar to Simulation; however, the difference is that every role is specified by researchers for every single participant in order to find a particular result that is previously proposed as hypothesis. It branch is focuses on interactions and final results.

\section{Applying Learning Path Branch.}

According to proposed activity and following lines raised in LIMEM 3D METHOD, for this kind of use (study of a specific topic) it is recommended to use learning path branch. This method variant allows teachers to design a series of strategies based on the use of four windows, applicable over any topic, in order that students can develop their own learning process with the monitor and support of teachers in a synchronous or asynchronous way. As a first step learning path branch proposes the following application:

\subsection{Selection of the Virtual Immersive Environment}

Within the features to evaluate in order to choose a 3D Virtual platform, teachers should seek that Immersive virtual environment guarantee the characteristics of Corporeity of the avatars and the environment as minimum. Interactivity between avatars and with the elements of the virtual world and finally persistence; in other words, not to disappear when going out the environment. Avatars are user representations. The user "lives" that world through a virtual "I" that is called "avatar" [10]. Additional to this, selected virtual world should offer wide possibilities to change avatar characteristics such as: body, face, hair, skin, and dress among others. Taking into account these characteristics in a preliminary design of the experiment, 4 different metaverses were evaluated, they were: Open Sim, Second Life, Unity and Vastpark. Teachers should compare their characteristics and choose the one with the best score obtained according to the case of use raised for the test in question. For defining this aspect there has been used the Virtual tool World Finder, from the page: http://www.daden.co.uk, which offers the possibility to compare the 4 platforms listed according to the specific selection of parameters.

The consultation on that page showed as result that the appropriate environment was SecondLife, here there is attached the list of chosen parameters and the score obtained for each platform:

As additional argument, the MVI more active and used in higher education is SL, launched in 2003 by Linden Lab, where universities make presence not only as a pedagogical tool, but also to make known to the world and attend to different educational plans[2]. Furthermore, this platform was chosen because its physics engine is advanced (Havok 4), users can hear and see the video and audio streaming within Second Life which is compatible with MPEG audio and 


\begin{tabular}{|l|l|}
\hline $\begin{array}{l}\text { Can build and customise } \\
\text { in-world: }\end{array}$ & (rather than use an external 3D design tool or ask us to change everything) \\
\hline $\begin{array}{l}\text { Highest possible quality } \\
\text { graphics: }\end{array}$ & $\begin{array}{l}\text { (yes this is a use case not technical requirement, and note that not virtual world will currently } \\
\text { match the best computer game) }\end{array}$ \\
\hline $\begin{array}{l}\text { NEED TO MODEL A LARGE } \\
\text { AREA (> } 1 \text { sq km): }\end{array}$ & N/A \\
\hline Custom client: & (e.g. no vendor branding, only functions needed by user etc.) \\
\hline Engagement mode: & (This is about users per activity - it is assumed that there will always be multiple concurrent users) \\
\hline Runs in browser (with plugin): & (no 3D virtual world runs yet in a browser without a plugin) \\
\hline Runs on mobile: & N/A \\
\hline Deploy on own servers: & (i.e. behind firewall to keep data secure) \\
\hline Robustness/security of code: & (i.e. minimal chance of code failures or exploitation) \\
\hline Import of existing 3D models: & (e.g. from Collada, 3D Studio max etc) \\
\hline Lowest Cost Possible: & N/A \\
\hline Security of Supply: & (combination of size of user base and likelihood of vendor still being in business in 5 years) \\
\hline
\end{tabular}

N/E: Not Apply.

The best match for your requirements is Second Life with a score of 257 .

Second Life scored 257.

Unity scored 243.

OpenSim scored 245.

Vastpark scored 217.

OggVorbis formats (it is required to install Quick time).

However, at this time the problematic aspect is the necessity of the machine, which to run smoothly with the platform must fit with the minimum characteristics required by www.secondlife.com. And they are:

Internet Connection: Cable or DSL Cable or DSL Operating System: XP, Vista or Windows 7. CPU with SSE2 support, including Intel Pentium 4, Pentium M, Core or Atom, AMD Athlon 64 or higher. $1.5 \mathrm{GHz}$ (XP), 2-GHz (Vista) 32-bit (x86) or higher. RAM: 1 GB or more. Screen Resolution: 1024x768 pixels or higher graphics card and XP or higher operating system.

\subsection{Adequacy or Searching of Appropriate} Environments for the Development of the Thematic to Be Implemented

Depending on how the environment is adequate or it is developed (according to the case), this will be attractive or not to the student (in this case the user), who receive plans of implementation in small groups. Instructors use these plans to determine the work on SecondLife and the selection of learning tools that students, as a group, are introduced according to their position [11].

SecondLife is based on a metaphor of a real estate located in an ocean, in this world users can buy islands (land portions according to user needs). These islands can be "developed", which means that any 3D artifact such as buildings, cars, clothes, etc. ... can be built using different kind of programs developed for this issues such as: SIMM ON A STICK, which simulates a 3D environment and permit to convert my team on served and user, build and export these constructions. Use Open Crocket or other creating programs of 3D objects that allow us to export or do rezzing (create or put something from your inventory to the virtual world) such as MAYA 3D[12], 3D Tin[13], AUTOCAD[14], ThinkerCad[15], K-3D[16], Art of Illusion[17], TopMod 3D[18], Google Sketch Up[19], Blender[20], OpenScad[21], Rhinoceros[22], Solid Works[23]and others, as well as use public Sandboxes (places where you can build and then make a copy of the work to save in an inventory or apply on an avatar or island) to make buildings to be reused. It must also take into account that it is necessary, in some cases, resort to using scripting language for SecondLife [3], due to is in this programming 
language that have to be develop the artifacts behavior.

Additionally, there is a large market of components (reusable buildings or objects) that are readily available via the web or on SecondLife Marketplace (https://marketplace.secondlife.com/) and other related pages.

However, the use of environments already recreated is recommended given that it reduces applied effort and time to launch. It is a perfect election if some islands fit to the purpose of teaching experience and if teacher does not have long practice with construction in metaverses.

The right election between a simple construction or existent built islands, based on teaching experience needs, offer to users the same platform characteristics which are very similar to virtual classroom characteristics such as: using interaction tools such as discussion forums, live chats and email, and that offer us certain advantages as: a more friendly environment for users, ease of configuration and the use of integrated tools (email, forums, chat, etc.). Integration on Internet. Management of a single program: the browser. Ease of adapting of content [24], are sufficient to obtain good results. It is so to set a section within an island we use prims (primitive object) or primitive (generally cubes extracted from an environment). Keep in mind that each island has an area of $512 \mathrm{~m}^{2}$, and that has a total of 15,000 prims (on SecondLife the term "prim" is used to refer to primitive objects. Except your avatar (AV or AVI), the floor of the simulator and the trees, all the objects on SecondLife are made of Prims. http://wiki.secondlife.com/wiki/Acerca_de_los_Prims) to build approximately 117 new objects.

\subsection{Training Students}

For the learning path process to be successful, and teaching-learning interactions to be fluent and enjoyed, teachers have to design a short training immersive environment such as: how to move and set-up their avatars, how to use different avatar views, how to use
Ip Voice, chat, photos, gestures and teleportation, how to use the land map and how to find and add people to your friend list and into the virtual world.

The success in this process sets the tone for the following activities and guarantees the comfort for the rest of the experience.

\subsection{Defining the Screen Based on Prims for Our Experiment.}

According to experimental 3D LIMEM METHOD, it is necessary to build four screens with their content previously designed, each one for a specific function within the practice and all of their content previously represented on a blog. To start the process of its construction we can use primitives from the 3D environment and use the incorporated tools in order to model the required screens.

Second life, and in general other 3D Worlds, are well equipped with a series of tools that permit users to build, move, turn, cut, paste, group, paint, in general personalized every single aspect over one primitive. This flexibility makes it possible to recreate screens with different characteristics and contents according to the planned application.

We can also make constructions of those screens in programs previously mentioned and to export or do rezzing (create or put something from your inventory to the virtual world), as well as use public Sandboxes (places where you can build and then make a copy of the work to save in an inventory or apply on an avatar or island) to make buildings to be reused. However, when choosing this option it must take into account that Secondlife charges us for calculating the amount of object prims we want to load.

\subsection{Using the Created Screens According to Experimental 3D LIMEM Method.}

For this specific adaptation we rely on the concept of active learning route proposed in the experimental method in development called 3D LIMEM, a strategy which in this case proposes the implementation of 
four screens based on the content of blogs (http://sleedch.blogspot.com, in this case) or web pages about the thematic chosen to treat. The method requires the use of four windows must fulfill with a specific mission within the teaching-learning context planned as:

Window 1: The function of this window is related to the presentation of the language thematic to develop with its corresponding grammatical aspects, explained in short and concrete ideas as possible.

Window 2: It window presents the language thematic applied into a common context or used by one specific character where study topic could be applying and understanding for students in a simple way.

Window 3: The learning path o route. It presents the trip of the learning route and the different activities that student should develop within the 3D world -it includes chosen environments, characters to interview, interactions that student have to stablish and others.

Window 4: Through this window, teachers should present different links to web pages or blogs with tests about the studied topic. Here there are attached the windows models built and the blog base used (Fig. 1):

The final result of the LIMEM 3D method implementation for this experiment generates the following contents for each window:

NOTICE: you can see the original contents on the blog through: http://sleedch.blogspot.com/

Summary: Window 1 is intended to provide the student has the summary of grammatical elements to be learned and to be used from the second language (Fig. 2).

Window 2 introduces the grammatical elements seen in window 1 through application of them within a context in particular (Fig. 3).

Window 3 proposes to visit different places within the immersive world in order to carry out various activities that will be tested and used as evidence in the training process (Fig. 4).

Finally, window 4 proposes a series of pages through which we can, through a test, evaluate the new knowledge learned (Fig. 5).

The learner interaction with the topic is focused on the four implemented screens; however, the application proposes through the screens is done throughout the whole process, either as a consultation media (Screen 1), as common exemplification of studied topic (Screen 2), calendar of activities to follow and locations to visit (Screen 3) or as training of learning (Screen 4). During the tour given on screen 3 students will generate different types of deliverables as: photos, maquinimias (video Sequences created into

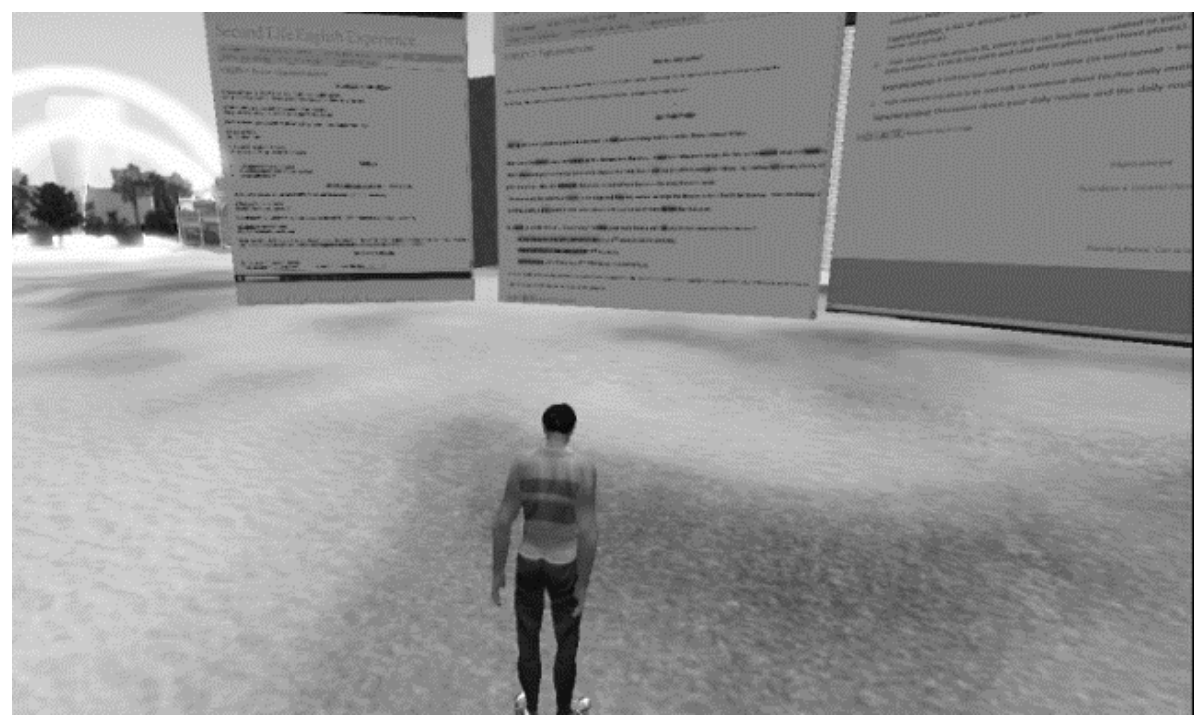

Fig. 1 Created Screens at EAFIT - SecondLife. 

Interaction Using the Limem 3d Method

$\Rightarrow 18$ sleedch.blogspot.com/p/screen-1.html
Página principal 1.INTRODUCTION: TO BE - PAST TENSE 2.Character: MICHAEL JACKSON 4.EXERCISES
SCREEN 3: Activities to develop. SCREEN 4: Test your knowledge 3.HOMEWORK: Learning way

SCREEN 1: Review - Gramattical stuctures

\section{SPELLING OF THE THIRD PERSON}

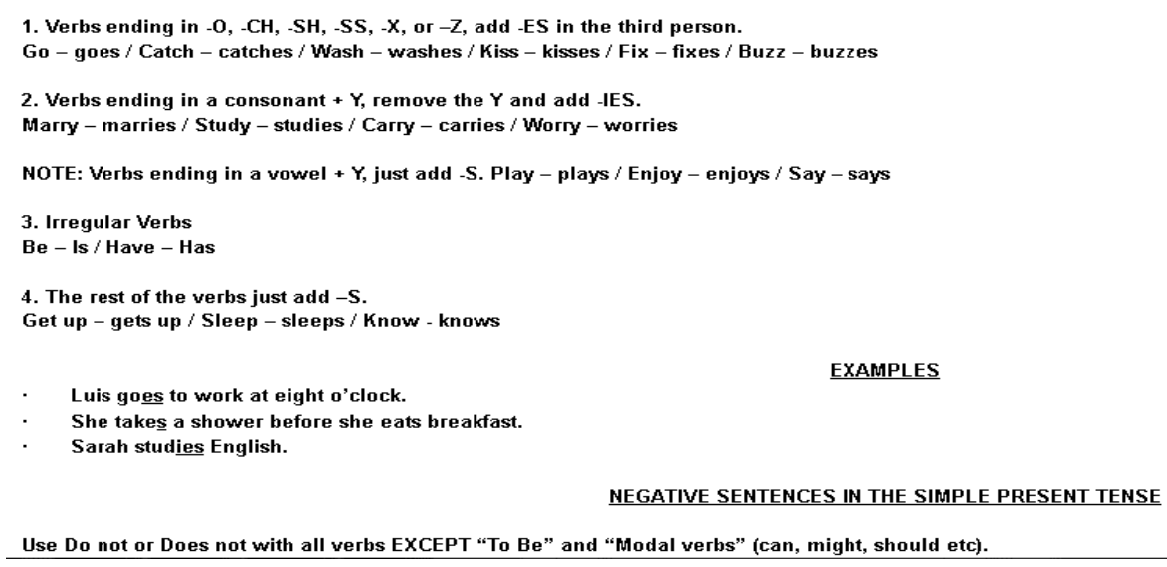

NEGATIVE SENTENCES IN THE SIMPLE PRESENT TENSE

Use Do not or Does not with all verbs EXCEPT "To Be" and "Modal verbs" (can, might, should etc).

Fig. 2 Window 1: third person rules grammatical structures review. (http://sleedch.blogspot.com/p/screen-1.html).

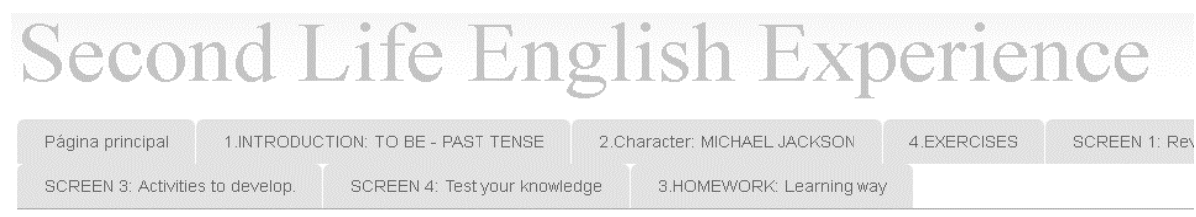

SCREEN 2: Topic presentation

What is a daily routine?

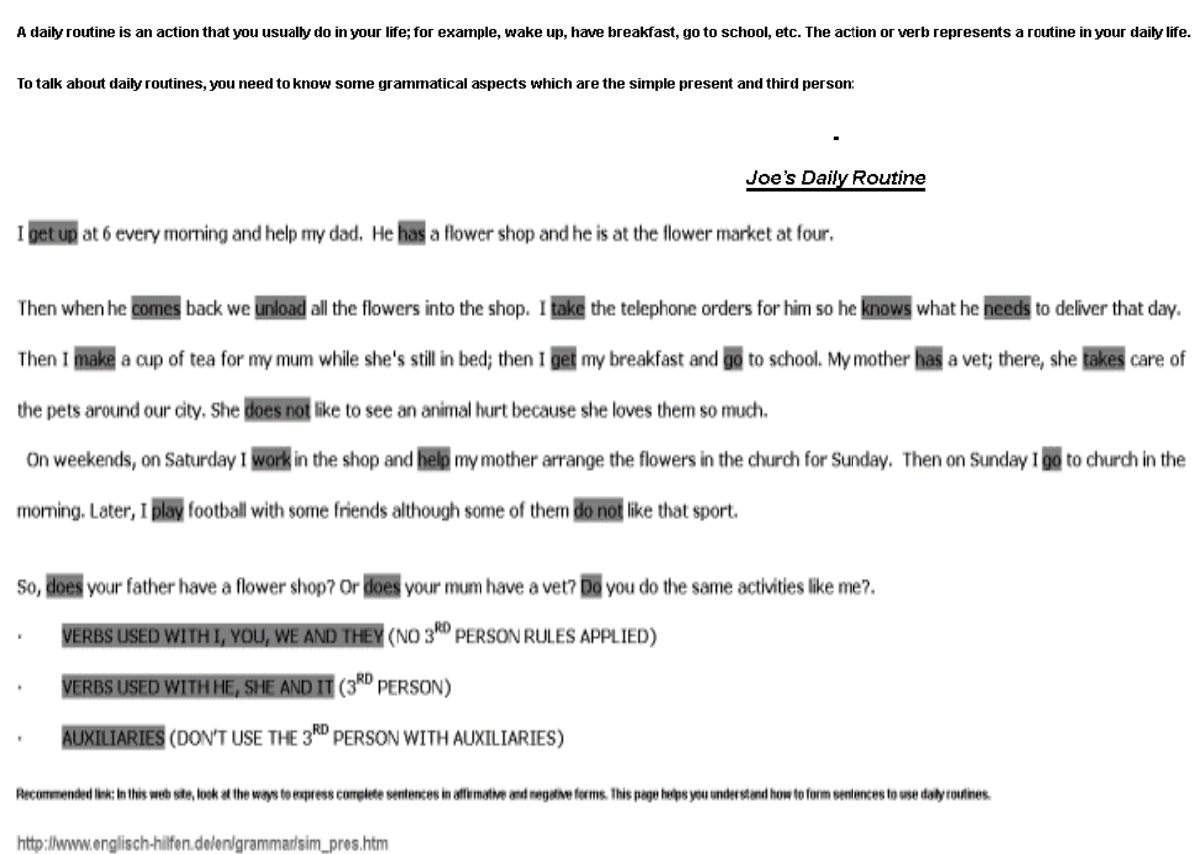

Fig. 3 Window 2: topic presentation, daily routine. (http://sleedch.blogspot.com/p/screen-2-topic-presentation.html). 


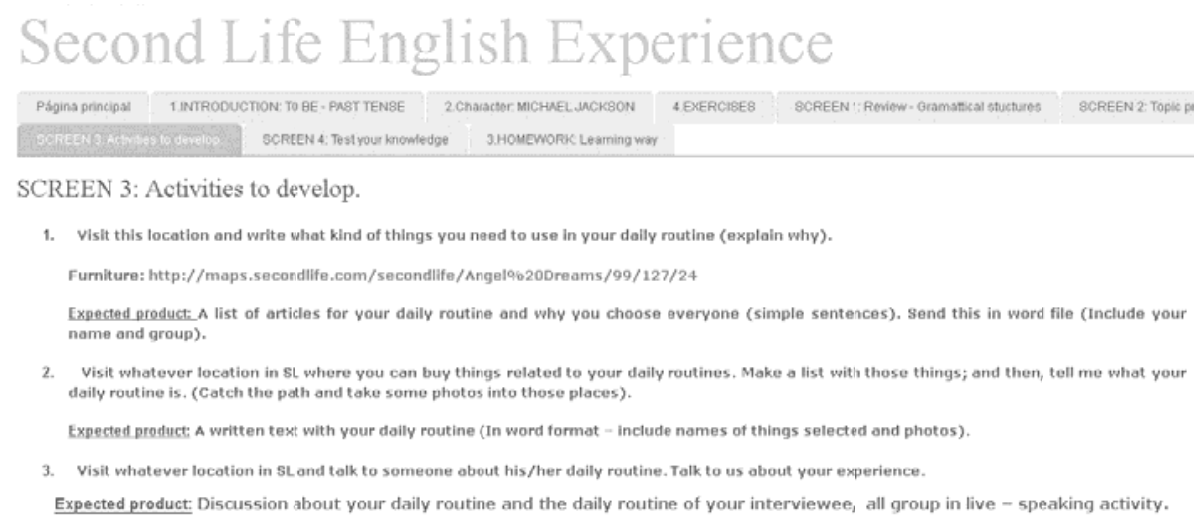

Fig. 4 Window 3: Activities to be developed, places visit and expected products. (http://sleedch.blogspot.com/p/screen-3-activities-to-develop.html).
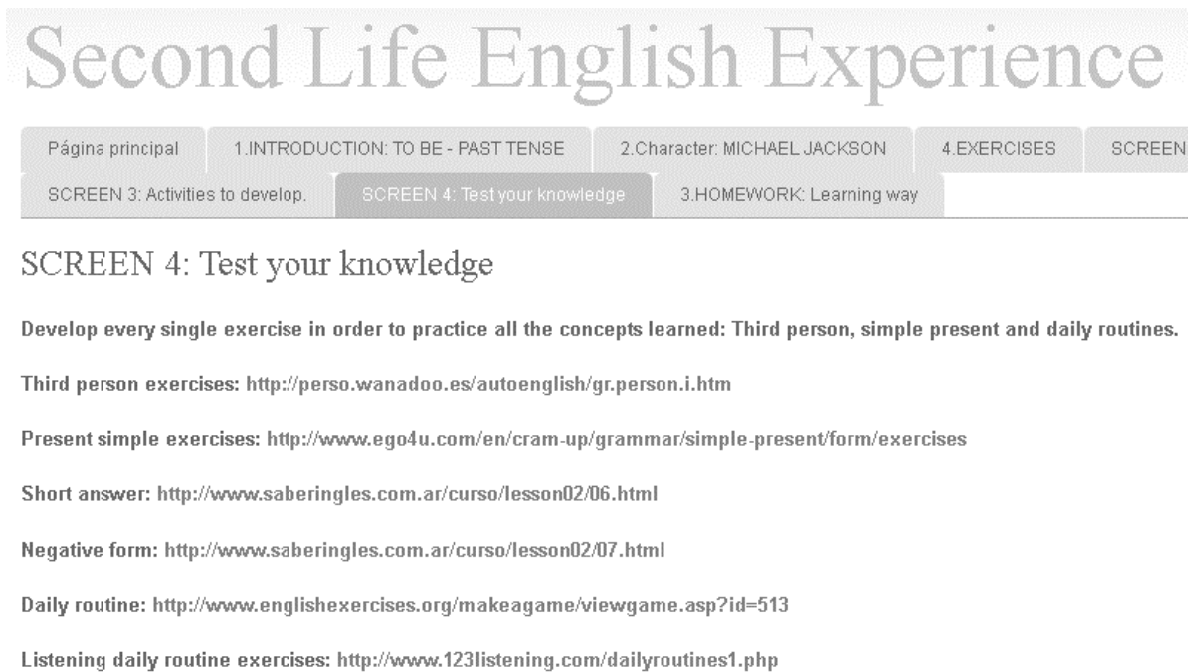

Fig. 5 Window 4: testing their knowledge, exercises. (http://sleedch.blogspot.com/p/screen-4-test-your-knowledge.html).

3D immersive environments), capture of chats, use of IP Voice, notes and others that his/her teacher checks at the same time, and to be able to keep constant communication via chat, teleport to a particular place in real time or use of email.

\section{Conclusions}

For its technical characteristics of interaction, capacity to support several users and to interact with other 3D platforms, the robustness of its development which includes excellent levels of security and continuous updates of its visor, as well as its imitation engine Havok 4, SecondLife becomes the tool for excellence for educational labor on 3D environments.

For performing a full teaching learning process does not necessarily require a complex development within a virtual world, according to Experimental 3D LIMEM METHOD it is possible to adapt the environment to its purposes. It could be useful and should not change the final results of learning-teaching interaction. Take what already exists and what is functional in order to favor the educational process proposed, as long as there exists a previous planning process and clear learning objectives, a proper training in the management of the platform to be used and the technological means for its ideal operation. Make only that you can find.

Making changes to the surrounding environment and import objects is not a technically demanding work given the advances in panel tools available for these effects. However, building 3D immersive environments and program events and object 
interactions could be a demanding process that requires a wide knowledge about own programing language platform.

The success of the technical implementation of teaching-learning process of a 3D immersive environment is based more on its previous planning than in the manipulation of the available items, and in good internet connection (bandwidth) and hardware components that guarantees the fluency of the expected interactions.

The field is promising for the future and requires more research processes that reinforce the proposed hypothesis in this article. In a first article based on the same research it is presented the final results of the application process [25], a second article presented a summary of the same topic explained in this paper [26].

\section{References}

[1] Siemens, George. 2007. Conectivismo: Una teoria de aprendizaje para la era digital. Traduccion: Diego E. Leal Fonseca.

[2] Baker, S. C., Wentz, R. K., and Woods, M. M. 2009. "Using Virtual Worlds in Education: Second Life ${ }^{\circledR}$ as an Educational Tool.” Teaching of Psychology 36: 59-64.

[3] Johannes, S., and Conrad, H. 1965. "Designing in Second Life: Identity Construction and Learning in a Virtual Informal Environment. Journal of Online Engineering Education, Vol. 1, No. 1, Article 2. School of Engineering Education, Purdue University, USA.R. W. Lucky, “Automatic equalization for digital communication," Bell Syst. Tech. J., vol. 44, no. 4, pp. 547-88.

[4] Garrison, D. R., and Anderson, T. 2005. Ele-learning enelsiglo XXI: Investigacion y practica. Octaedro Barcelona Espana.

[5] Arias, T., and Mauricio, D. 2014. Metodo 3D LIMEM. Instituto Netsys, Colombia.

[6] Grupo Avatar. "Hacemo sexperiment osqueen la vida real resultarianpeligrosos.” En: Second Life. [enlinea]. (2008). $\begin{array}{llll}\text { [Consultado } & 8 & \text { jun. }\end{array}$ Disponibleenhttp://blog.pucp.edu.pe/item/23389/hacemos -experimentos-que-en-la-vida-real-resultarian-peligrosos\# more.

[7] Duguid, M. M., and Goncalo, J. A. 2011. Living large: The powerful overestimate their own height [Electronicversion]. Retrieved [08-06-2012], from Cornell University, ILR School site: http://digitalcommons.ilr.cornell.edu/articles/456/.

[8] Quinche, J. C., and Franci, L. G. 2011. Entornos Virtuales 3D, Alternativa Pedagogica para el Fomento del Aprendizaje Colaborativo y Gestion del Conocimiento en Uniminuto. Corporacion Universitaria Minuto de Dios, Bogota-Colombia.

[9] Teresa, R., and Miguel, B. 2011. Secondlife: una herramienta para la mejora de las dinamicas de comunicacion y aprendizaje en la ensenanza online. VI conversatorio de 2011 en Secondlife. Grupo Ciberimaginario. Universidades San Martin de Porres y Rey Juan Carlos. Espana.

[10] Banos, G., Miguel, R. G., and Teresa, C. 2012. V Simposio Las Sociedades ante el Reto Digital. Universidad del Norte. Bogota, Colombia.

[11] Liski, R., and Syren, I. 2011. Experiences of operating and studying in second life: conclusions for training design. Turkish Online Journal of Distance Education-TOJDE August 2011, ISSN 1302-6488. Volume: 12 Number: 3/2 Special Issue on Second Life Applications in Distance Education Article 3.

[12] http://www.autodesk.es/products/maya/overview

[13] http://www.3dtin.com

[14] http://www.autodesk.com/products/autocad/overview

[15] https://tinkercad.com

[16] http://www.k-3d.org/wiki/Main_Page

[17] http://www.artofillusion.org

[18] https://sites.google.com/site/topmod3d

[19] http://www.sketchup.com/Blender

[20] http://www.blender.org

[21] http://www.openscad.org

[22] https://www.rhino3d.com/es

[23] Solid Works.

[24] Mendoza, Hellyss. Modelo de evaluacion de plataformas tecnologicas virtuales. Escuela de computacion Valera estado-Trujillo. Universidad "Valle del Momboy". Venezuela.

[25] Arias, T., Mauricio, D., and Helmuth, T. 2013. "Educational Effectiveness of Using a Shared Virtual Immersive Environment for Teaching English as a Second Language.” Presented at the 17th International Conference on Image Processing, Computer Vision, \& Pattern Recognition IPCV'13.July 2013, ISBN \#: 1-60132-253-4. Volume: II. Number: article: 46. Pages926-932.

[26] Arias, T., Mauricio, D., and Helmuth, T. 2014. "Adequacy of an Immersive Environment as a Teaching-Learning Tool Applying Experimental 3d LIMEM Method.” Presented at the International Conference on Frontiers in Education: Computer Science and Computer Engineering FECS'14. July 2014, ISBN

[27] \#: ISBN \#: 1-60132-271-2. Volume: I. article: 27. Pages 183-18. 